\title{
Phenology of Woody Species: a Review
}

\author{
Humberto Gonzalez Rodriguez ${ }^{1}$, Ratikanta Maiti2* and N. C. Sarkar ${ }^{3}$
}

\author{
${ }^{1}$ Universidad Autonoma de Nuevo Leon, Facultad de Ciencias Forestales, Carr. Nac. No 85, km 145, Linares, Nuevo Leon, \\ 67700 Mexico \\ ${ }^{2}$ RKM Foundation, Fracc. Valle de las Flores, Avenida del Museo \# 1118, San Nicolas de los Garza, Nuevo Leon. 66430, Mexico \\ ${ }^{3}$ Dept. of ASEPAN, Institute of Agriculture, Visva-Bharati, Sriniketan, West Bengal (731 236), India
}

\section{Article History}

Manuscript No. AR669a

Received in $9^{\text {th }}$ March, 2014

Received in revised form $19^{\text {th }}$ August, 2014

Accepted in final form $27^{\text {th }}$ August, 2014

\section{Correspondence to}

ratikanta.maiti@gmail.com

\section{Keywords}

Woody trees, phenology, leaf, flowering, fruiting, productivity, climate

\begin{abstract}
An attempt has been made to synthesize a brief account on research advances on various phases of phenology. Climate has positive impact on the timing of phenology; cold-air drainage may influence the start of leaf growth, however leaf phenology in tropical evergreen forests is not determined by the seasonality of precipitation. Climate warming in late winter and spring may enhance sensitivity of the growing season's spatial response due to the relationship of beginning date to temperature. Elevated temperature strongly influences greater in $\mathrm{C}_{3}$ plants than in $\mathrm{C}_{4}$ plants but the disadvantages of warming may be considerably attenuated by elevated $\mathrm{CO}_{2}$, especially for $\mathrm{C}_{3}$ grasses. Species with high wood densities can able to store only limited quantities of water in their trunks; leaf fall in these species occurred during the dry season. Flowering phenology may be changing faster and precipitation may play a more important role in semi-arid grasslands than in humid-temperate systems. Peak flowering and fruiting are dependent on seasons for both endemic and non-endemic species. Population sensitivity to global warming might be stable for a given species, in spite of its possible local adaptation. It might be possible for ecologists to establish comprehensive networks for long-term monitoring of potential photosynthetic capacity from regional to global scales by linking satellite-based programme. Use of satellite-derived metrics, such as VARI, may be used for evaluating the spatial patterns and temporal dynamics of species composition across broad geographic regions.
\end{abstract}

\section{Introduction}

Phenology determines the different phases of life cycle of a woody species (trees or shrubs) in a forest ecosystem which have direct impact on the productivity of forest ecosystem and its biodiversity. This consists of seedling, vegetative and reproductive phase of a species. The vegetative phenology depends on the growth of leaves and stems while the reproductive phenology determines flowering, and fruiting including seed dispersal. This in turn has direct impact on the production of seeds in the forest ecosystem.

Phenology is a very important event in the life cycle of a plant Changes of plant phonological events have been identified as indicator of climate change. In northeastern Mexico, there exist different types of vegetation such as pine forest, oak forest, the pine-oak forest, and the subtropical woodlands, typical of the semi-arid plains (Vargas, 1999). The productivity of the forest ecosystem is highly dependent efficient and fruiting of the woody species growing in this region. We are giving herwith a brief account of research advances on different phases of phenology of woody species.

\section{Vegetative Phenology}

Leaf phenology determines the timing of the emergence of leaves; its expansion and leaf fall. This responsible for the capture of carbon dioxide and photosynthesis related to the productivity of the tree. With the advent of favourable climate the treess start the initiation of young leaves leading to formation of leaf flush necessary for the growth of plant by photosynthesis and for the productivity of the forest.

A study has been made on the phenology of Quercus ithaburensis with emphasis on the effect of fire during three consecutive years in Yahudia Nature Reserve, Israel. Budbreak occurred mostly in February with minor bud breaks in March-April, May and September-October. Trees shed 
leaves in October through January with a peak in DecemberJanuary, but even during these months at least $10 \%$ of the trees remained evergreen. Acorns generally began to ripen in November and shedding extended from December until January. The percentage of acorns attaining full ripeness varied considerably from branch to branch and from year to year, reaching approximately $20 \%$ of the number of acorns found in May. Ripe acorns appeared exclusively on 2-year old branches. The degree of fire damage to trees greatly depended on the intensity of the fire, which in turn depended on weather conditions, quantity of dry pasture vegetation, and the location of the tree relative to cairns. Reduction of the bulk of dry pasture vegetation, affected the number of trees harmed, both as to their revival and their re-budding potential. Heavy grazing reduced to nearly half the number of trees suffering damage. After an early summer fire, budding was monitored, but not after a late summer fire (Kaplan and Gutman, 1999). Red alder (Alnus rubra Bong.) is the most abundant deciduous tree on the Pacific coast of North America and its use as a timber species is increasing. Gonsamo et al. (2013) investigated aaptive variation in growth, phenology, cold tolerance and nitrogen fixation of red alder (Alnus rubra Bong.). They examined the pattern and degree of variation in physiological and growth traits among 59 families of red alder, and relate this variation to the climates of family origin. Significant genetic variation among regions was observed in height, diameter, canopy cover, cold hardiness and nitrogen concentration of red alder families. Differences in climates and available moisture explained most of the among-family variation in autumn canopy cover, bud burst, and cold hardiness, whereas temperature and length of the growing season of origin was associated with amongfamily differences in cold hardiness and growth. It is assessed that phenology, cold hardiness, survival and height of tightly adapted families will be most affected by assisted migration or long-term climate change, but some families do not show strong adaptation to their climate of origin and will be more able to acclimate to deviations in climate. Jeganathan et al. (2014) studied remotely sensed trends in the phenology of northern high latitude terrestrial vegetation, controlling for land cover change and vegetation type. Trends in the start or end of growing season (SOS, EOS) of terrestrial vegetation reported previously as latitudinal averages limit the ability to investigate the effects of land cover change and species-wise conditioning on the presented vegetation phenology information. The rate of change in SOS and EOS over 25 years was estimated, aggregated and scrutinised at different measurement levels: a) vegetation type, b) percentage vegetative cover, c) core area, d) percentage forest cover loss, and e) latitude zones. Overall, the increasing trend in EOS during senescence (September to November) was greater in magnitude than the decreasing trend in SOS during spring (March to May) and the change in EOS was more consistent and greater than that in SOS.

Vitasse et al. (2009) made a comparative study on phenological sensitivities to temperature of seven woody species between each other and within-species between two geographical areas using both altitudinal and temporal gradients (Abies alba, Acer pseudoplatanus, Carpinus betulus, Fagus sylvatica, Fraxinus excelsior, Ilex aquifolium and Quercus petraea). Across the temporal gradient, they found significant advances in leaf unfolding for oak and ash whereas no significant advance was observed for beech and hornbeam. They emphasized that phenological sensitivity to temperature was very similar between the two geographically separated populations in Pyrenees and Fontainebleau forests. Thereby, oak had the strongest sensitivity in altitudinal and temporal gradient, respectively and beech had the lowest. The results suggest that population sensitivity to global warming might be stable for a given species, in spite of its possible local adaptation. Vitasse et al. (2011) assessed the effects of climate change on the phenology of European temperate trees. They showed that most flushing models are able to predict accurately the observed flushing dates. Within a temperature range of about $7{ }^{\circ} \mathrm{C}$, the altitudinal gradient is particularly relevant to calibrate phenological models. It was assessed that most of the phenological models used were able to explain and predict accurately the leaf unfolding date for all the tree species considered, whereas they failed to predict senescence date for two out of four deciduous species. Dates of leaf unfolding are expected to be advanced in the coming decades and dates of senescence to be delayed. The results suggest that chilling temperature could be insufficient for some species at low elevation with winter temperatures rising in the next decades. The simulations showed species differences in lengthening of canopy duration and consequently suggested changes in the competitive balance between species over the current century

Zhang et al. (2013) investigated fig tree phenology at the northern range limit of monoecious Ficus in China. Fig trees (Ficus) are a species-rich group of mainly tropical and subtropical plants that are of ecological importance because of the large numbers of vertebrates that utilise their figs for food. Relatively few trees produced figs, and very few retained figs throughout the winter. Despite this, new crops produced in spring were pollinated, with seasonally migrant pollinators from plants growing further south the most likely pollen vectors. An inability to initiate new crops at low temperatures may limit the distribution of monoecious fig trees to warmer areas. Lee (2011) studied combined effect of elevated $\mathrm{CO}_{2}$ and temperature on the growth and phenology of two annual $\mathrm{C}_{3}$ and $\mathrm{C}_{4}$ weedy species. They used two annual species of $\mathrm{C}_{3}$ and $\mathrm{C}_{4}$ plants, Chenopodium album $\left(\mathrm{C}_{3}\right)$ and Setaria viridis $\left(\mathrm{C}_{4}\right)$ 
grown under three different environmental conditions: (1) ambient temperature and $\mathrm{CO}_{2}$ (control), (2) $4^{\circ} \mathrm{C}$ elevated temperature with ambient $\mathrm{CO}_{2}$, and (3) combined conditions of $4^{\circ} \mathrm{C}$ elevated temperature and 1.8 times ambient $\mathrm{CO}_{2}(\mathrm{CT} 4)$. The plant phonology was generally more affected by increased temperature than elevated $\mathrm{CO}_{2}$ during all growth stages. With a $4^{\circ} \mathrm{C}$ increase in temperature, the timings of emergence were advanced by approximately 26 days (d) for C. album and approximately $35 \mathrm{~d}$ for $S$. viridis. The flowering times were also advanced, by 50 days for C. album and by 31.5 days for $S$. viridis. With the advanced phenology observed in the elevated temperature plots, the growth temperatures during the vegetative stage were similar to the values in the control plot. The results suggest that elevated temperature strongly influences biomass production in annual grasses during the reproductive stage compared to the vegetative growth stage and that these effects may be greater in $\mathrm{C}_{3}$ plants than in $\mathrm{C}_{4}$ plants. However, the disadvantages of warming may be considerably attenuated by elevated $\mathrm{CO}_{2}$, especially for $\mathrm{C}_{3}$ grasses. Lesica and Kittelson (2010) reported that precipitation and temperature are associated with advanced flowering phenology in a semiarid grassland. They recorded first-bloom date of common spring wildflowers in a semi-arid grassland in the Rocky Mountains, USA from 1995 through 2008 and analyzed these data along with mean monthly temperature and precipitation. Advanced flowering predominated; $75 \%$ of the 32 species displayed a negative linear regression slope, and this trend was strong for nine species (slope $<1.0, p<0.10$ ). Only one species showed a strong trend for later flowering. Mean advance for all 32 species was 0.61 days/year and mean advance for the nine species displaying a strong tendency to flower earlier was 1.6 days/year. Species flowering early showed stronger trends toward advanced flowering than later species. The results suggest that flowering phenology may be changing faster and precipitation may play a more important role in semi-arid grasslands than in humid-temperate systems. Guo et al. (2013) evaluated long-term records (1963-2008) of chestnut (Castanea mollissima Blume) first flowering, leaf coloring and length of the growing season from Beijing, China. Phenological dates were related with daily temperatures (subjected to an 11-day running mean) for the 12 months leading up to the respective events, using Partial Least Squares (PLS) regression.

Fisher et al. (2006) studied green leaf phenology using Landsat resolution from the field to the satellite. Green vegetation areal abundance for each scene was measured from spectral mixture analysis and a single set of endmembers. The leaf area signal was fitted with a logistic-growth simulating sigmoid curve to derive phenological markers (half-maximum leaf-onset and offset). Spring leaf-onset dates in homogenous stands of deciduous forests showed significant and persistent local variability. The local variability was validated with multiple spring time ground observations $\left(r^{2}=0.91\right)$. The highest degree of verified small-scale variation observed where contiguous forests exhibited leaf-onset gradients of 10-14 days over short distances $(<500 \mathrm{~m})$. This suggests that microclimates resulting from springtime cold-air drainage may influence the start of leaf growth; every $4.16 \mathrm{~m}$ loss in elevation delayed spring leaf onset by 1 day. The results reveal that deciduous forests leaf out 5-7 days earlier than comparable rural areas.

Leaf phenology of tropical evergreen forests affects carbon and water fluxes. Xiao et al. (2006) detected leaf phenology of seasonally moist tropical forests in South America with multi-temporal MODIS images. The results showed a large dynamic range and spatial variations of annual maximum EVI for evergreen forest canopies in the region. This suggests that leaf phenology in tropical evergreen forests is not determined by the seasonality of precipitation.

Chen and Xu (2012) reported that temperature controls on the spatial pattern of tree phenology in China's temperate zone. They used Ulmus pumila leaf unfolding and leaf fall data collected at 46 stations during the 1986-2005 period to construct and validate daily temperature-based spatial phenology models. These models allowed simulation of the 20 -year mean and yearly spatial patterns of $U$. pumila growing season beginning and end dates. The results show that spatial patterns of daily temperatures within the optimum spring and autumn length periods control spatial patterns of growing season beginning and end dates, respectively. Both mean and yearly spatial phenology models perform satisfactorily in predicting beginning and end dates of the $U$. pumila growing season at external stations. Further analysis showed that the negative spatial response of yearly beginning date to spring daily temperature was stronger in warmer years than in colder years. This finding suggests that climate warming in late winter and spring may enhance sensitivity of the growing season's spatial response due to the relationship of beginning date to temperature. Guyon et al. (2011) studied the impact of the elevation variations in the seasonal dynamics of a temperate deciduous broadleaf forested ecosystem on the onset of spring leaf unfolding. They utilized the analysis of multi-annual time-series of VEGETATION data obtained from the French Pyrenees Mountain Region (FPMR), in conjunction with simultaneous ground-based observations of leaf phenology for two dominant tree species in the region (oak and beech). The elevation variations in leaf flushing timing were found to be consistent with those measured in situ $\left(\mathrm{R}^{2}>0.95\right)$. The expected estimation error of satellite-based leaf unfolding date for a given elevation was approximately 2 days. The earlywoodvessel area of ring-porous species is found to be related to environmental factors prevailing during the time of vessel formation. Saitoh et al. (2012) assessed the use of camera- 
based indices for characterizing canopy phenology in relation to gross primary production in a deciduous broad-leaved and an evergreen coniferous forest in Japan. The different relationship was observed at different phenological stages. The results suggest that it might be possible for ecologists to establish comprehensive networks for long-term monitoring of potential photosynthetic capacity from regional to global scales by linking satellite-based, in situ spectra-based, and in situ camera-based índices. In a Bolivian subtropical humid forest, Felton et al. (2006) reported differences in gap size, vegetation structure, regeneration and phenology between anthropogenic and natural gaps in a reduced-impact logged and unlogged forest. Logging gaps were significantly larger than natural gaps (d.f. 1, variance ratio (vr.) 6.38, $p=0.014$ ) and had significantly lower coverage of lianas (d.f. 1, vr. $8.64, p<0.01$ ). In larger gaps, microclimatic conditions favour the regeneration of non-commercial pioneer species. They proposed that ground disturbance during bole removal causes higher rates of mortality to shade-tolerant species in advanced stages of regeneration. This removes the competitive height advantage needed by shade-tolerant species to compete within gaps, and thus further promotes the opportunity for pioneer species to dominate gap regeneration. The observed differences between anthropogenic and natural tree-fall gaps are of direct importance to forest managers to understand the impact of the reduced logging ion the regeneration of commercial tree species in Bolivian forestry concessions.

Climate plays an important role in determining tree phenology. Broadhead et al. (2003) studied the relationship beween tree phenology and water availability in semi-arid agroforestry systems on Melia volkensii, which sheds its leaves twice a year, Senna spectabilisand Gliricidia sepium, which shed their leaves once during the long dry season, and the evergreen Croton megalocarpus. Phenological patterns were examined in relation to climatic conditions in the bimodal rainfall regions of Kenya to identify factors which dictate the intensity of competition between trees and crops. Although essentially evergreen, leaf cover in $C$ megalocarpus decreased during the dry season and increased rapidly during periods of high rainfall. G. sepium exhibited a period of low leaf cover during the long dry season and did not regain full leaf cover until mid-way through the short rains. Pinto et al. (2011) studied in detail the phenology and growth dynamics in Mediterranean evergreen oaks om relation to effects of environmental conditions and water relations. The shoot elongation in oak was mainly dependent on nutrient availability in top soil. There existed a strong and positive relationships between annual shoot growth and long-term cumulative rainfall. The results reveals that budburst in Quercus suber is triggered by temperature within specific photoperiod limits and budburst in Q.suber occurs about six weeks later than in Quercus ilex. In water-limited sites, shoot elongation is restricted by tree water stress. In well-watered sites shoot elongation is higher and depends on nutrients. Climate change will tend to anticipate budburst and decrease shoot elongation. Lima and Rodal (2010) undertook a study to relate the phenology and wood density of 90 woody species growing in the semi-arid region of northeastern Brazil. Wood density varied between $0.29 \mathrm{~g} \mathrm{~cm}^{-3}$ and $0.83 \mathrm{~g} \mathrm{~cm}^{-3}$. Leaf fall in these species occurred during the transition period between the rainy and the dry season. It occurred earlier than in species with denser wood. Leaf flush among low wood density species was positively related to the photoperiod. Species with high wood densities, on the other hand, were strongly dependent on rainfall for leaf flush, flowering, and fruiting, as they can are able to store only limited quantities of water in their trunks; leaf fall in these species occurred during the dry season. Modelling phenology is crucial to assess the impact of climate change on the length of the canopy duration and the productivity of terrestrial ecosystems. Terrestrial ecosystems are highly sensitive to climatic changes in early and late growing seasons. Gonsamo, et al. (2012) predicted deciduous forest carbon uptake phenology by upscaling FLUXNET. Land surface phenology (LSP), determining the seasonal pattern of variation in vegetated land surfaces observed from synoptic sensors, has been given emphasis due to its role as a surrogate in detecting the impact of climate change. Although several studies have been conducted on the growing season LSP, studies on the net carbon uptake phenology (CUP) defined as the detrended zero-crossing timing of net ecosystem productivity from a source to a sink in spring and vice versa in autumn, have been scarce. They test a hypothesis that the mean monthly surface temperature and LSP derived from remote sensing observations explain the CUP both in spring and autumn seasons. They predicted the observed CUP in spring and autumn within 8 day mean errors, equivalent to the temporal resolution of the 8-day composite remote sensing dataset used in this study for the four flux tower sites. They presented remote sensing of carbon uptake phenology (CUP). CUP is estimated from land surface phenology (LSP) and air temperature $\mathrm{CO}_{2}$ flux and remote sensing measurements gave comparable CUP estimates. The observed CUP phenology is predicted within 8 day mean errors. The vegetation phenology is related to ecosystem responses to climate variability and change. Melaas et al. (2013) determined interannual variation in deciduous broadleaf forest phenology using Landsat TM/ETM+data. Results revealed that spring and autumn phenological transition dates estimated from Landsat data agree closely with in situ measurements of phenology collected at the Harvard Forest in central Massachusetts, and that Landsat-derived estimates for the start and end of the growing season in Southern. Ma 
et al. (2013) studied spatial patterns and temporal dynamics in savanna vegetation phenology across the North Australian Tropical Transect in Savannas possess complex assemblages of multiple tree, shrub, and grass vegetation strata, each showing variable phenological responses to seasonal climate and environmental variables. Phenology of Acacia dominated in savannas showed high responses to hydroclimatic variability. The variability in annual precipitation alone explains $80 \%$ of the variances in the length of greening season across the major vegetation groups. They also found that increased variation in the timing of phenology was associated with a decreasing tree-grass ratio.

\section{Reproductive Phenology}

Krishnan(2004) studied reproductive phenology of 27 endemic and 33 non-endemic species, monitored at monthly intervals for 20 months in a mid-elevation wet forest in the Southern Western Ghats. Peak flowering occurred during the dry and post-monsoon seasons for the endemic species, while the non-endemic species flowered during the dry season. Fruiting peak was found in the dry season for endemic species and during monsoon for non-endemics. The flowering and fruiting pattern in narrow and broad endemic species was uniform. The implications of the result for conservation are emphasized. In this respect, Krishnan (2004) in a study on the reproductive phenology of endemic species in a wet forest of the Western Ghats, south India, reported that the peak flowering was observed during the dry and post-monsoon seasons for the endemic species, while the non-endemic species flowered during the dry season.

Salinas-Peba and Parra-Tabla (2007) studied the reproductive phenology, breeding system and pollination of the tropical tree Manilkara zapota in two contrasting environments: mediumheight, subdeciduous forest, and homegardens (solares) in a Mayan community in the state of Yucatan in Mexico. Significant differences were found between environments both in the temporal distribution of flower and mature fruit production, as well as in the proportion of mature fruits. Homegarden trees showed the greatest fruit production. Hand pollination experiments showed that M. zapota is selfcompatible, and that there is pollinator limitation for fruit production in trees that grow in homegardens. They proposed that water and soil nutrients are the main factors limiting $M$. zapota fruit production in forests, while in homegardens the main factor appears to be pollinator availability. Borges et al. (2009) investigated the phenology, pollination, and breeding system of C. echinata from October, 2004 to December, 2006 in the Tapacura Ecological Station, northeastern Brazil. Flowering occurred mainly in the dry season and the peak of seed dispersal was at the beginning of the wet season. Anthesis is diurnal, lasting 1 day. The flowers are zygomorphic, yellow, sweetscented, and the effective pollinators were mainly mediumsized to large bees of the genera Centris and Xylocopa, together with the introduced Apis mellifera. Nectar volume and sugar concentration averaged $2.9 \pm 1.0 \mu \mathrm{L}$ and $29.5 \pm 9.4 \%$, respectively. The pollination biology and breeding system of C. echinata are discussed. Data on the reproductive biology of the genus are scarce, revealing the predominance of bee pollination and SI system, with the occurrence of late-acting self-incompatibility mechanisms in some species.

Kuaraksa et al. (2012) studied the phenology of dioecious Ficus spp. tree species and its importance for forest restoration projects. Ficus spp. are important tree species in tropical forest ecosystems and considerd vital to include them in tree planting for forest restoration programs. Therefore, the reproductive phenology of seven dioecious Ficus species (Ficus auriculata, F. fulva, F. hispida, F. oligodon, F. semicordata, F. Triloba and F. variegata) was studied at Doi Suthep-Pui National Park, Northern Thailand, in order to provide useful data to support forest restoration projects. The study generated scientifically-based recommendations that will be useful for development of efficient forest restoration programs that maintain keystone resources in tropical forest ecosystems. The study on the reproductive phenology of dioecious Ficus species in Northern Thailand reveal that optimum times/places of seed collection for propagation of Ficus spp. propagation. Results suggest the use of Ficus as keystone species in forest restoration projects. Measures need to be taken to sustain vital relationships between fig-trees and their pollinator. Vina et al. (2012) studied the relationship between floristic similarity and vegetated land surface phenology and its implications for the synoptic monitoring of species diversity at broad geographic regions using remote sensors. It is suggested that the analysis of the temporal dynamics of pigments through the use of satellite-derived metrics, such as VARI, may be used for evaluating the spatial patterns and temporal dynamics of species composition across broad geographic regions. Olsson et al. (2013) utilized the model-specific forcing units accumulated by the observed day of budburst, and tested for covariation with bio-climatic gradients. For most models, temperature gradients showed significant variability in forcing units accumulated at day of budburst. It is concluded that the budburst models were not able to fully explain the response to inter-annual variations in temperature conditions. Zhang et al. (2013) reported in China that low temperature reduces the activity of pollinators in figs owing to which very few figs flower in winter seasons. Vilhar et al. (2013) described methodologies for harmonized phenological assessments based on a few developmental phases: flushing, flowering, secondary flushing, color change, and leaf/needle fall. Because, manual 
phenological observations are time consuming, more recently, the use of terrestrial digital image photography for forest phenology monitoring has been adopted. All indirect methods using optical vegetation indices from digital camera or NDVI sensors need to be validated against ground observations, for which manual tree phenological observations from the forest monitoring plots are often used.

\section{Fruit Phenology}

Phenology of fruits starting from fruit iniation up to seed dispersal play an important role in the productivity of tress in diverse ecosystem with varying climatic conditions. Chmielewski et al. (2004) studied climate changes and trends in phenology of fruit trees and field crops in Germany, 19612000. The strongest shift in plant development occurred for the very early spring phases. The late spring phases and summer phases reacted also to the increased temperatures, but they usually show lower trends. Hart et al. (2013) studied the fruiting phenology of four forest fragments in the Ngele Mistbelt Forest complex, which forms part of the Eastern Mistbelt Forests in Kwa Zulu-Natal, using fruit-fall traps. It is hypothesized that fruit availability would vary with forest fragment size and with season. Fruiting varied significantly between months for all fragments, and where annual variations were insignificant. The number of fruiting species per fragment varied significantly and numbers of fruiting species per fragment per month were generally low. Tree species varied in their fruiting patterns between fragments and fruiting of Afrocarpus/ Podocarpus trees and the implications for endemic, endangered Cape Parrots are discussed as an example. In summary, these forests have variable and unpredictable fruiting behaviour between fragments. These results emphasized the need to conserve forest fragments of varying sizes as a network to provide a year round supply of fruits to frugivores.

Cortees-Flores et al. (2013) studied fruiting phenology of seed dispersal syndromes in a Mexican Neotropical temperate forest. In respect to phenological patterns, the anemochorous species presented a fruiting peak in the middle of the dry season (February) while the autochorous and zoochorous species had a fruiting peak at the beginning of this season (December). The three dispersal syndromes showed a negative correlation between precipitation and the number of species fruiting. The autochorous and zoochorous species also showed inverse relationships with temperature. The results suggest a complex relationship between fruiting phenology and dispersal syndromes influenced by abiotic (precipitation and temperature) and biotic factors (growth form and seed dispersal) in the forest studied. The results of this study contribute to understanding the key processes in assessing these communities, which should be considered when defining strategies for their conservation, management and restoration of this ecosystem.

Powe and Bentz (2014) studied phenology and densitydependent dispersal predict patterns of mountain pine beetle (Dendroctonus ponderosae) impact. They developed and parameterized a mechanistic model describing mountain pine beetle (Dendroctonus ponderosae Hopkins) population demographics and dispersal across a landscape. Model components include temperature-dependent phenology, host tree colonization determined by an Allee effect, and randomwalk dispersal with motility conditioned by host tree density. Forest Service aerial detection surveys, and remotely sensed host tree density data were used to parameterize the model using a maximum likelihood approach. In both study sites, the model was highly accurate $(>84 \%)$ in predicting annual pattern formation when the model was re-initiated each year with the location of new patches of infested trees. Prediction of annual population growth at both sites was also good $(>90 \%)$. The model extends previous research by providing a mechanistic description of the link between motility, dispersal and temperature-dependent MPB phenology.

Selwyn and Parthasarathy (2007) investigated fruiting phenology of 22 woody species belonging to 18 families in a tropical dry evergreen forest on the Coromandel coast of India in relation to plant life-forms, physiognomic groups, dispersal modes, and climatic constraints for 1 year at monthly intervals, in a tropical dry evergreen forest at Oorani $\left(12^{\circ} 11^{\prime} \mathrm{N}, 79^{0} 57^{\prime} \mathrm{E}\right)$ on the Coromandel coast of India. At the community level, bimodal fruiting pattern was prevailed, with a major peak in the dry season and a minor one in the early rainy season. There was no significant difference in the frequency of species at three fruiting stages across the life-form categories and many species of upper and lower canopy trees and lianas were in the ripe fruiting phase during the late dry season. The fruit maturation period was much longer for the wet season fruiting brevi-deciduous species than evergreen and deciduous species that fruited during the dry season. The variation in timing of fruiting behaviour among zoochorous species demonstrated less seasonality and zoochorous fruits were observed throughout the year. Fruiting in anemochorous species peaked during the driest months and dryness favoured the dissemination of seeds. The fruiting patterns observed in the tropical dry evergreen forest across various plant traits were comparable with patterns recorded in other tropical seasonal forests. Du et al. (2009) studied the seed dispersal phenology and dispersal syndromes in a subtropical broad-leaved forest of China. The $1300.5 \mathrm{~m}^{2}$ seed traps collected 69,115 mature seeds, representing 27 species (belonging to 24 genera, and 15 families) in 12 months. Overall, the community level seed rain study revealed that one marked peak in seed number occurred in the middle of dry season; zoochory was the principal 
dispersal mode of woody plants in subtropical forest, and dry seasons favor seed dispersal by animal and wind.

\section{Conclusion}

Phenology determines the timing of different phases of life cycle of a plant such as leaf phenology, flowering, fruiting and seed dispersal. This plays an important role in the productivity of forest ecosystem as well as for efficient management of forests. Wide variability in phenology reflects the variability in the productivity. A comprehensive understanding on phenology is required for future course of research.

\section{References}

Borges, L. A., Sobrinho, M.S., Lopes, A.V., 2009. Phenology, pollination, and breeding system of the threatened tree Caesalpinia echinata Lam. (Fabaceae), and a review of studies on the reproductive biology in the genus. FloraMorphology, Distribution, Functional Ecology of Plants 204(2), 111-130.

Broadhead, J.S., Ong, C.K., Black, C.R., 2003. Tree phenology and water availability in semi-arid agroforestry systems. Forest Ecology and Management 180(1-3), 61-73

Chen, X., Xu, L., 2012. Temperature controls on the spatial pattern of tree phenology in China's temperate zone. Agricultural and Forest Meteorology 154-155, 195-202.

Chmielewski, F.M., Müller, A., and Ekko Bruns. 2004. Fruiting phenology of palms and trees in an Atlantic rainforestlandbridge island. Flora-Morphology, Distribution, Functional Ecology of Plants 204(2), 131-145.

Cortes-Flores, J., Andresen, E., Cornejo-Tenorio, G., IbarraManríquez, G., 2013 Fruiting phenology of seed dispersal syndromes in a Mexican Neotropical temperate forest. Forest Ecology and Management 289, 445-454.

Du, Y., Mi, X., Liu, X., Chen, L., Ma, K., 2009. Seed dispersal phenology and dispersal syndromes in a subtropical broad-leaved forest of China. Forest Ecology and Management 258(7), 1147-1152.

Felton, A., Felto n, M.A., Wood, J., Lindenmayer, D.B., 2006. Vegetation structure, phenology, and regeneration in the natural and anthropogenic tree-fall gaps of a reducedimpact logged subtropical Bolivian forest. Forest Ecology and Management 235(1- 3), 186-193.

Fisher, J.I., Mustard, J.F., Vadeboncoeurm, M.A., 2006. Green leaf phenology at Landsat resolution: Scaling from the field to the satellite. Remote Sensing of Environment 100(2), 265-279.

Gonsamo, A., Chen J.M., Wu, C., Dragoni, D., 2012. Predicting deciduous forest carbon uptake phenology by upscaling FLUXNET measurements using remote sensing data. Agricultural and Forest Meteorology 165, 127-135.
Gonsamo, A., Chen, J.M., Odorico, P.D., Porter, R.B., Lacourse, T., Hawkins, B.J., Yanchuk, A., 2013. Adaptive variation in growth, phenology, cold tolerance and nitrogen fixation of red alder (Alnus rubra Bong.). Forest Ecology and Management 291, 357-366.

Guo, L., Dai, J., Ranjitkar, S., Xuc, J., Luedeling, E., 2013. Response of chestnut phenology in China to climate variation and change. Agricultural and Forest Meteorology 180, 164-172.

Guyon, D., Guillot, M., Vitasse, Y., Cardot, H., Hagolle, O., Delzon, S., Wigneron, J.P., 2011. Monitoring elevation variations in leaf phenology of deciduous broadleaf forests from SPOT/VEGETATION time-series. Remote Sensing of Environment 115(2), 615-627.

Hart, L.A., Grieve, G.R.H., Downs, C.T., 2013. Fruiting phenology and implications of fruit availability in the fragmented Ngele Forest Complex, KwaZulu-Natal, South Africa. South African Journal of Botany 88, 296-305.

Jeganathan, C., Dash, J., Atkinson, P.M., 2014. Remotely sensed trends in the phenology of northern high latitude terrestrial vegetation, controlling for land cover change and vegetation type. Remote Sensing of Environment 143, 154-170.

Kaplan, D., Gutman, M., 1999. Phenology of Quercus ithaburensis with emphasis on the effect of fire. Forest Ecology and Management 115(1), 61-70.

Krishnan, R.M., 2004. Reproductive phenology of endemic understorey assemblage in a wet forest of the Western Ghats, south India. Flora - Morphology, Distribution, Functional Ecology of Plants 199(4), 351-359.

Kuaraksa, C., Elliott, S., Hossaert-Mckey, M., 2012. The phenology of dioecious Ficus spp. tree species and its importance for forest restoration projects. Forest Ecology and Management 265, 82-93.

Lee, J.S., 2011. Combined effect of elevated $\mathrm{CO}_{2}$ and temperature on the growth and phenology of two annual $\mathrm{C}_{3}$ and $\mathrm{C}_{4}$ weedy species. Agriculture, Ecosystems \& Environment 140(3-4), 484-491.

Lesica, P., Kittelson, P.M., 2010. Precipitation and temperature are associated with advanced flowering phenology in a semi-arid grassland. Journal of Arid Environments 74(9), 1013-1017.

Lima, A.L.A., Rodal, M.J.N., 2010. Phenology and wood density of plants growing in the semi-arid region of northeastern Brazil. Journal of Arid Environments 74(11), 1363-1373.

Luedeling, E., Gassner, A., 2012. Partial Least Squares Regression for analyzing walnut phenology in California. Agricultural and Forest Meteorology 158-159, 43-52.

Ma, X., Huete, A., Yu, Q., Coupe, N.R., Davies, K., Broich, M., Ratana, P., Beringer, J., Hutley, L.B., Cleverly, 
J., Boulain, N., Eamus, D., 2013. Spatial patterns and temporal dynamics in savanna vegetation phenology across the North Australian Tropical Transect. Remote Sensing of Environment 139, 97-115.

Melaas, E.K., Friedl, M.A., Zhu, Z., 2013. Detecting interannual variation in deciduous broadleaf forest phenology using Landsat TM/ETM+data. Remote Sensing of Environment 132, 176-185.

Olsson, C., Bolmgren, K., Lindström, J., Jönsson, A.M., 2013. Performance of tree phenology models along a bioclimatic gradient in Sweden. Ecological Modelling 266, 103-117.

Pinto, C.A., Henriques, M.O., Figueiredo, J.P., David, J.S., Abreu, F.G., Pereira, J.S., Correia, I., David, T.S., 2011. Phenology and growth dynamics in Mediterranean evergreen oaks: Effects of environmental conditions and water relations. Forest Ecology and Management 262(3), 500-508.

Powe, J.A., Bentz, B.J., 2014. Phenology and densitydependent dispersal predict patterns of mountain pine beetle (Dendroctonus ponderosae) impact. Ecological Modelling 273, 173-185.

Saitoh, T.M., Nagai, S., Saigusa, N., Kobayashi, H., Suzuki, R., Nasahara, K.N., Muraoka, H., 2012. Assessing the use of camera-based indices for characterizing canopy phenology in relation to gross primary production in a deciduous broad-leaved and an evergreen coniferous forest in Japan. Ecological Informatics 11, 45-54.

Salinas-Peba, L., Parra-Tabla, V., 2007. Phenology and pollination of Manilkara zapota in forest and homegardens. Forest Ecology and Management 248(3), 136-142.

Selwyn, M.A., Parthasarathy, N., 2007. Fruiting phenology in a tropical dry evergreen forest on the Coromandel coast of India in relation to plant life-forms, physiognomic groups, dispersal modes, and climatic constraints. Flora - Morphology, Distribution, Functional Ecology of Plants 202(5), 371-382.

Vilhar, U., Beuker, E., Mizunuma, T., Skudnik., Lebourgeois, F., Soudani, K., Wilkinson, M., 2013. Chapter 9 - Tree Phenology. In: Forest Monitoring-Methods for terrestrial investigations in Europe with an overview of North America and Asia. Developments in Environmental Science 12, 169-182.

Viña, A., Tuanmu, M.N., Xu, W., Li, Y., Qi, J., Ouyang, Z., Liu, J., 2012. Relationship between floristic similarity and vegetated land surface phenology: Implications for the synoptic monitoring of species diversity at broad geographic regions. Remote Sensing of Environment 121, 488-496.

Vitasse, Y., Delzon, S., Dufrene, E., Pontailler, JY., Louvet, J.M., Kremer, A., Michalet, R., 2009. Leaf phenology sensitivity to temperature in European trees: Do within-species populations exhibit similar responses? Agricultural and Forest Meteorology 149(5), 735-744.

Vitasse, Y., François, C., Delpierre, N., Dufrene, E., Kremer, A., Chuine, I., Delzon, S., 2011. Assessing the effects of climate change on the phenology of European temperate trees. Agricultural and Forest Meteorology 151(7), 969-980.

Xiao, X., Hagen S., Zhang, Q., Keller, M., Moore III, B., 2006. Detecting leaf phenology of seasonally moist tropical forests in South America with multi-temporal MODIS images. Remote Sensing of Environment 103(4), 465-473.

Zhang, L.S., Compton, S.G., Xiao, H., Lu, Q., Chen, Y., 2014. Living on the edge: Fig tree phenology at the northern range limit of monoecious Ficus in China. Acta Oecologica 57, 135-141. 